\title{
Comparison of Satisfaction of Body Parts and the Success Levels of the Teams That Participated in Universities Handball $2^{\text {nd }}$ League Competitions*
}

\author{
Zeynep F. Dinç ${ }^{1}$, Kamil Dikici ${ }^{1}$, İlknur Özdemir ${ }^{2}$ \\ ${ }^{1}$ Physical Education and Sports High School, Çukurova University, Adana, Turkey \\ ${ }^{2}$ Acıpayam Vocational High School, Pamukkale University, Denizli, Turkey \\ Correspondence: İlknur Özdemir, Pamukkale University, Denizli, Turkey.
}

Received: November 19, 2017

Accepted: December 12, 2017 Online Published: December 31, 2017

doi:10.11114/jets.v5i13.2907

URL: https://doi.org/10.11114/jets.v5i13.2907

\begin{abstract}
The study was conducted to determine and compare the satisfaction levels of the students participating in the Universities $2^{\text {nd }}$ Handball League competitions on body parts and body features and the success of their teams. The study group consisted of $\mathrm{n}=213$ (111 female, 102 male) students between 18-24 years of age who participated in 2016-2017 Universities $2^{\text {nd }}$ Handball League competitions ( 8 Female Teams, 8 Male Teams). The "Body Parts and Body Features Satisfaction Scale" was used as the measurement tool. There are 26 items for women and 27 items for men in this scale. The One-Way Variance Analysis and Tukey Test were used in the comparison of the satisfaction scores of the male handball players from their body parts with the success levels in competitions, and the Kruskal Wallis Test and Mann Whitney U-Test were used in female participants.

According to the satisfaction from body parts and features average scores, the differences between the male and female teams were found to be statistically significant $(p<0,05)$. These differences were detected in İbrahim Çeçen, Erzincan and Doğu Akdeniz University teams in men; and in Atatürk, Sütçü İmam and Erciyes University teams in women.

As a result, although there was a statistically significant difference between the average satisfaction scores of the teams, which were the $1^{\text {st }}$ and the last in the tournament, in terms of body parts and features, it was also determined that this situation was not influential on the success rating of the teams.
\end{abstract}

Keywords: body part, satisfaction, gender perception, handball

\section{Introduction}

Body image is defined as the perception style of an individual about his/her body. Body image includes cognitive dimensions about the body (experiences, perceptions and considerations about the body), and affective dimensions (whether the individual is satisfied with his/her body, whether s/he loves and accepts his/her body, etc.) (Bektaş, 2004).

The theories explain the body image by referring to social structures, the explicit and implicit messages sent by the society to the individual, and the perception of women finding their body slim and attractive (Morrison, Kalin, \& Morrison, 2004), men finding their body muscled (Dale, Cusumano, \& Kevin , 1997).

With the widespread use of the Internet and technology, people may reach the idealized images in the media in a fast manner, and compare themselves with these ideal models. The ideal types shown in the media impose physical attractiveness standards to the society, care for slim women and muscled men, bring gender-based standards about physical attractiveness, and the weight and shape of the body (Solomon, Venuti, Hodges, Ianuzzelli \& Chambliss, 2001; Lindwall \& Hassmen, 2004).

While positive features are associated with success, attractiveness and being slim, negative features like laziness and slowness are associated with being fat (Morris, Cooper, \& Cooper, 1989; Brownell, 1991; Ogden \& Evans, 1996). Positive features are associated with beauty and negative features are associated with ugliness from early childhood to adulthood.

*This article was supported by Pamukkale University Scientific Research Projects Commission. 
With increasing age, individuals constantly make evaluations about their bodies and body images through social comparisons (Butler , 1998), and struggle to reach the body shape and size that is considered proper for them. For the purpose of reaching the ideal body structure, they make investments for a new body shape by making use of various alternatives (drugs, aesthetic surgeries, diets, clothing type, etc.) or various sportive activities. They receive support by dealing with some sportive activities they are interested in (individual sports, extreme sports, team sports) to develop a healthy body image.

Individuals dealing with professional sports participate in trainings and competitions to obtain and develop sportive performance. As a result of physical, physiological and psychological loadings on the body, sportive performance parameters increase, and individuals mostly achieve their goals in having a healthy and satisfying body. The acquired body satisfaction perception ensures that individuals feel positive about themselves, and also support them in achieving success in their sports branches.

The present study was conducted for the purpose of comparing the satisfaction levels of the students who participated in the Universities Handball $2^{\text {nd }}$ League Competition from their body parts and body characteristics and also to compare the success levels of the teams.

\section{Material and Method}

The Study Group consisted of the students who participated in The study group consisted of $n=213$ (111 female, 102 male) students between 18-24 years of age who participated in 2016-2017 Universities 2nd Handball League competitions ( 8 Female Teams, 8 Male Teams). The "Body Parts and Body Features Satisfaction Scale" was used as the measurement tool in the study, which was developed by Berscheid and Bohrnstedt (1972), and whose adaptation for Turkish was performed by Gökdoğan (1988). There are 26 items for women and 27 items for men in this scale. The items were evaluated by using a 5-Point Likert Scale varying between "Being extremely satisfied about the body image", and "Being not satisfied about the body image". High scores refer to the satisfaction level about the body image.

The achievements of the teams were ranked according to the scores obtained from the competitions. The achievement ranking of the universities in males were as follows; Cumhuriyet (1), Doğu Akdeniz (2), Erzincan (3), Düzce (4), Mehmet Akif (5), Bilkent (6), İbrahim Çeçen (7) and Sütçü İmam (8); and Gazi Osman Paşa (1), Bozok (2), Yeditepe (3), Atatürk (4), Sütçü İmam (5), Selçuk (6), Erciyes (7), Karamanoğlu Mehmet Bey (8) Universities in female participants.

\subsection{The Analysis of the Data}

The SPSS 16.00 Program was used in the analyses of the data. The normality of the data was tested for males and females in comparing the averages of the total scores of satisfaction level from the body parts and features by considering the team successes of the university students. It was determined that the variances were homogenous in the comparison of body satisfaction averages according to their success levels in the male handball players. It was also determined that the variances were not homogenous in female handball players.

The One-Way Variance Analysis (ANOVA-F Test) was used for the statistical comparisons in male teams, and the Tukey Test, which is one of the Post Hoc Tests, was used to determine between which universities the differences were. The Kruskal Wallis Test was used in female teams; and the Manny Whitney U Test was used for paired comparisons. The statistical significance level was taken as $\mathrm{p}<0,05$. 


\section{Findings}

Table 1. The Results of the One-Way Variance Analysis (ANOVA) Made to Determine Whether the Average Scores of the Male Students Participating the Universities Handball $2^{\text {nd }}$ League Competitions Received from the "Body Parts and Body Features Satisfaction Scale" in Team Success Ranking Varied according to Team Success Variable; the Arithmetic Average Values, and Standard Deviation Values

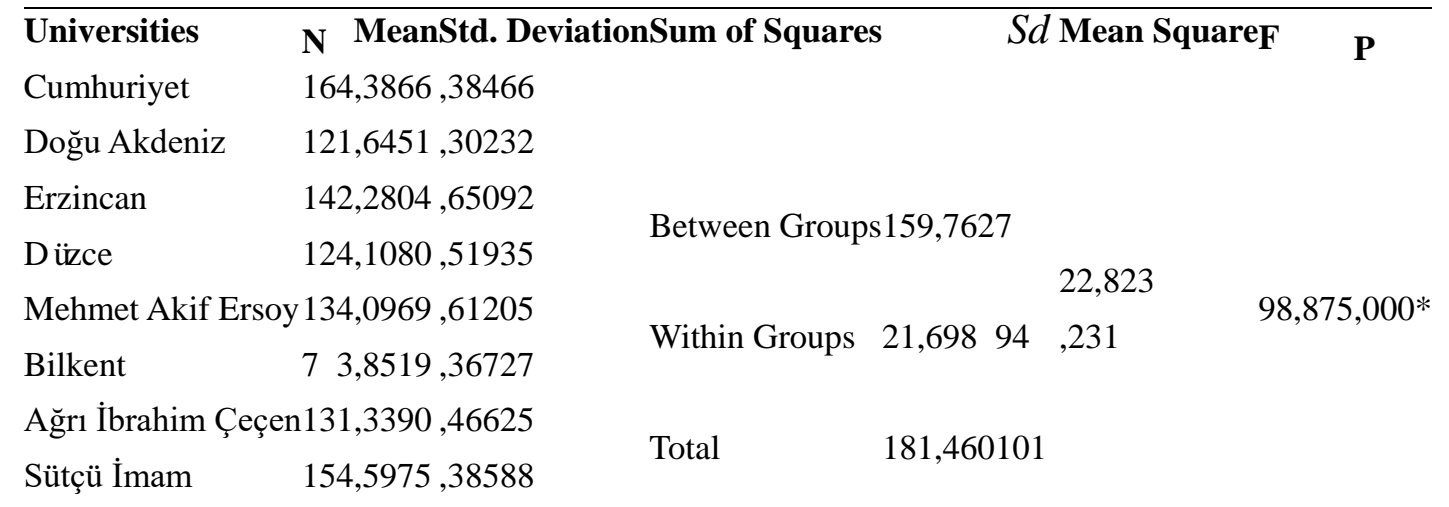

Significance level $\mathrm{p}<0,05^{*}$

The universities that had the lowest average values in being satisfied with the body parts and features according to the results of the competition success levels are; Ağrı İbrahim Çeçen $(x=1,33 \pm, 46)$, Doğu Akdeniz $(x=1,64 \pm, 30)$, Erzincan $(x=2,28 \pm, 65)$, Bilkent $(x=3,85 \pm, 36)$ Universities, and those with higher scores were Sütçü İmam $(x=4,59 \pm, 38)$, Cumhuriyet $(x=4,38 \pm, 38)$, Düzce $(x=4,10 \pm, 51)$, Mehmet Akif Ersoy $(x=4,09 \pm, 61)$ Universities, respectively. A statistically significant difference was determined between the body image satisfaction levels of the male handball players at university teams according to the success level ranking in competitions $(\mathrm{p}<0,05)$.

Table 2. The Results of the Tukey Test Applied to Determine the Differentiation of the Average Scores Received by Male Students Participating in the Universities Handball $2^{\text {nd }}$ League Competitions from "Body Parts and Body Features Satisfaction Scale" according to University Team Success Level Variable

\begin{tabular}{llll}
\hline (I) Universities & (J) University with Difference & $(\mathrm{I}-\mathrm{J})$ Mean Difference & $\mathrm{p}$ \\
\hline Ağrı İbrahim Çeçen & Mehmet Akif Ersoy & $-2,75783^{*}$ &, $000^{*}$ \\
& Sütçü İmam & $-3,25850^{*}$ &, $000^{*}$ \\
Düzce & $2,76899^{*}$ &, $000^{*}$ \\
Cumhuriyet & $3,04754^{*}$ &, $000^{*}$ \\
Bilkent & $2,51282^{*}$ &, $000^{*}$ \\
Erzincan &, $94139^{*}$ &, $000^{*}$ \\
Erzincan &,$- 63536^{*}$ &, $024^{*}$ \\
& Mehmet Akif Ersoy &, $000^{*}$ \\
Sütçü İmam & $-2,45180^{*}$ &, $000^{*}$ \\
Erzincan & Düzce & $-2,95247^{*}$ &, $000^{*}$ \\
& Bilkent & $-2,46296^{*}$ &, $000^{*}$ \\
& Cumhuriyet & $-2,20679^{*}$ &, $000^{*}$ \\
Cumhuriyet & $2,74151^{*}$ &, $000^{*}$ \\
& Mehmet Akif Ersoy & $2,10615^{*}$ &, $000^{*}$ \\
& Sütçü İmam & $-1,81644^{*}$ &, $000^{*}$ \\
& Düzce & $-2,31711^{*}$ &, $000^{*}$ \\
& Bilkent & $-1,82760^{*}$ &, $000^{*}$ \\
& Sütçü İmam & $-1,57143^{*}$ &, $022^{*}$ \\
\hline
\end{tabular}

Significance level $\mathrm{p}<0,05^{*}$

The average scores of being satisfied from the body parts and features according to competition success ranking showed statistically significant difference in male teams $(p<0,05)$. This difference shows that the handball players in İbrahim Çeçen, Erzincan and Doğu Akdeniz and Bilkent Universities are not satisfied with their body images. 
Table 3. The Results of the Kruskal Wallis-H Test Made to Determine Whether the Average Scores of the Female Students Participating the Universities Handball $2^{\text {nd }}$ League Competitions Received from the "Body Parts and Body Features Satisfaction Scale" in Team Success Ranking Varied according to Team Success Variable; the Arithmetic Average Values, and Standard Deviation Values

\begin{tabular}{|c|c|c|c|c|c|c|c|}
\hline Groups & $\mathrm{N}$ & Mean & Std. Deviation & Mean rank & Chi-square & sd & $\mathrm{p}$ \\
\hline Gazi Osman Paşa & 11 & 4,2098 & ,46960 & 67,32 & \multirow{8}{*}{23,726} & \multirow{8}{*}{7} & \multirow{8}{*}{,001 } \\
\hline Bozok & 15 & 4,0897 & ,63394 & 62,77 & & & \\
\hline Yeditepe & 15 & 4,0128 & ,30168 & 55,53 & & & \\
\hline Atatürk & 13 & 3,4793 & 37376 & 25,92 & & & \\
\hline Sütçü İmam & 16 & 3,7548 & ,75511 & 45,62 & & & \\
\hline Selçuk & 13 & 4,4704 & ,51701 & 79,42 & & & \\
\hline Erciyes & 15 & 3,7538 & 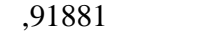 & 49,73 & & & \\
\hline Karamanoğlu Mehmet Bey & 11 & 4,2098 & ,46960 & 65,81 & & & \\
\hline
\end{tabular}

Significance level $\mathrm{p}<0,05^{*}$

The average scores of being satisfied from body parts and features according to the success levels in the competitions were determined as Atatürk $(x=3,47 \pm, 37)$, Erciyes $(x=3,75 \pm, 91)$, Sütçü İmam $(x=3,75 \pm, 75)$, Yeditepe $(x=4,01 \pm, 30)$, Bozok ( $x=4,08 \pm, 63)$, Gazi Osman Paşa and Karamanoğlu Mehmet Bey ( $x=4,20 \pm, 46)$, Selçuk $(x=4,47 \pm, 51)$ Universities. There is a statistically significant difference between the body image satisfaction levels of the female handball players playing at university teams according to the success levels ranking in competitions $(\mathrm{p}<0,05)$.

Table 4. The Results of the Mann Whitney U-Test Applied to Determine the Differentiation of Average Scores Received by Female Students Participating in the Universities Handball $2^{\text {nd }}$ League Competitions from "Body Parts and Body Features Satisfaction Scale" according to University Team Success Level Variable

\begin{tabular}{|c|c|c|c|c|c|}
\hline Groups & Mean rank & Sum of ranks & $\mathrm{U}$ & $\mathrm{Z}$ & $\mathrm{p}$ \\
\hline Atatürk & 11,04 & 143,50 & \multirow{2}{*}{52,500} & \multirow{2}{*}{$-2,260$} & \multirow{2}{*}{, $024^{*}$} \\
\hline Sütçü İmam & 18,22 & 291,50 & & & \\
\hline Atatürk & 7,69 & 100,00 & \multirow{2}{*}{9,000} & \multirow{2}{*}{$-3,876$} & \multirow{2}{*}{, $000^{*}$} \\
\hline Selçuk & 19,31 & 251,00 & & & \\
\hline Atatürk & 9,65 & 125,50 & \multirow{2}{*}{34,500} & \multirow{2}{*}{$-2,566$} & \multirow{2}{*}{, $010^{*}$} \\
\hline Karamanoğlu Mehmet Bey & 17,35 & 225,50 & & & \\
\hline Atatürk & 8,19 & 106,50 & \multirow{2}{*}{15,500} & \multirow{2}{*}{$-3,249$} & \multirow{2}{*}{, $001 *$} \\
\hline Gazi Osman Paşa & 17,59 & 193,50 & & & \\
\hline Atatürk & 8,85 & 115,00 & \multirow{2}{*}{24,000} & \multirow{2}{*}{$-3,390$} & \multirow{2}{*}{, $001 *$} \\
\hline Yeditepe & 19,40 & 291,00 & & & \\
\hline Atatürk & 9,88 & 128,50 & \multirow{2}{*}{37,500} & \multirow{2}{*}{$-2,767$} & \multirow{2}{*}{, $006^{*}$} \\
\hline Bozok & 18,50 & 277,50 & & & \\
\hline Yeditepe & 11,07 & 166,00 & \multirow{2}{*}{46,000} & \multirow{2}{*}{$-2,376$} & \multirow{2}{*}{, $017 *$} \\
\hline Selçuk & 18,46 & 240,00 & & & \\
\hline Sütçü İmam & 10,72 & 171,50 & \multirow{2}{*}{35,500} & \multirow{2}{*}{$-3,009$} & \multirow{2}{*}{, $003^{*}$} \\
\hline Selçuk & 20,27 & 263,50 & & & \\
\hline
\end{tabular}

Significance level $\mathrm{p}<0,05^{*}$

The average scores of being satisfied with the body parts and features showed significant difference according to the success level ranking in the competitions in female teams $(p<0,05)$. This result shows that the handball players of the Atatürk, Sütçü İmam and Erciyes University teams had lower body image satisfaction scores when compared with the other players from other universities.

\section{Result and Discussion}

The study was conducted for the purpose of comparing the ranking between the being satisfied with the body parts and features levels of the students who participated in Universities Handball $2^{\text {nd }}$ League competitions and their success levels as a team.

The body image satisfaction levels of the male handball players were determined to be lower in Ağrı İbrahim Çeçen, Doğu Akdeniz Erzincan and Bilkent University teams than the teams of Sütçü İmam, Cumhuriyet, Düzce and Mehmet Akif Ersoy Universities. In terms of the success rating of the teams, the ranking of universities was as follows; Cumhuriyet (1), Doğu Akdeniz (2), Erzincan(3), Düzce (4), Mehmet Akif (5), Bilkent (6), İbrahim Çeçen (7) and Sütçü İmam (8) Universities. The Doğu Akdeniz (2) and Erzincan (3) Universities, which had low body images, were among the first 3 teams; however, Sütçü İmam University (8), which had the highest body image levels, was the most unsuccessful team in the competitions. Ağrı İbrahim Çeçen University, which had the lowest body image, was the $7^{\text {th }}$ in the competitions. 
The body image satisfaction level averages of the female players who participated in the $2^{\text {nd }}$ League Handball Competitions, were determined to be lower in Atatürk, Erciyes, Sütçü İmam Universities than the Yeditepe, Bozok, Gazi Osman Paşa, Karamanoğlu Mehmet Bey, and Selçuk Universities. The success rating of the teams was as follows; Gazi Osman Paşa (1), Bozok (2), Yeditepe (3), Atatürk (4), Sütçü İmam (5), Selçuk (6), Erciyes (7), Karamanoğlu Mehmet Bey (8) University. Atatürk University, which had the lowest body image values in female handball players, completed the competitions as the $4^{\text {th }}$ university; Karamanoğlu Mehmet Bey University, which had one of the high body image scores, completed as the $8^{\text {th }}$ university; and Gazi Osman Paşa University completed the competitions as the $1^{\text {st }}$ university. On the other hand, Selçuk University, which had the highest average values, completed the competitions as the $6^{\text {th }}$ university. Unlike the male handball players, the first 3 teams in female players were Gazi Osman Paşa (1), Bozok (2), Yeditepe (3) Universities, which had high body image perception averages. However, Karamanoğlu Mehmet Bey University (8), which had high body image average, and Selçuk (6) University, which had the highest average values, were at the end of the list in success ranking.

When the literature on body image is reviewed, it is observed that previous studies reported to do regular exercises, physical activity and sports to improve a healthy body image (Turner, McFarlane, \& Van Der Kolk, 1996; Featherstone, 2010). It was also reported in previous studies that regular sports protect the health of individuals and improved the outer look of the body and the body image in a positive way. In addition, high body satisfaction is related with a good physical performance, and it was reported that men and women, who were physically active, were more satisfied from their bodies (Richman \& Shaffer, 2000; Philips \& Drummond, 2001; Kjelsas \& Augestad, 2004).

In the present study, the results showing that the university teams that had low body image satisfaction averages were successful in ranking in the competitions, and those with high body image values were the latest in the competitions are contrary to the results reported in the literature. In females; however, it was determined that the body image satisfaction levels of the teams with high success levels were high, which is similar to the results reported in the literature. However, it is considered that the definitive element in terms of success is not the body image, because Karamanoğlu Mehmet Bey University, which had the highest body image averages, was the latest in the competitions.

When the results of the study were analyzed, it was observed that the results were different in male and female participants in the comparison of success ranking and body image satisfaction scores. It was determined that the awareness and satisfaction rates were higher in female participants when compared with the males. The reason for this might be the fact that female individuals want to be admired more than males.

It was observed that the teams that had high body image scores in males and females had low results in competitions. This situation might be interpreted as sports players focus on achieving success by using their physical and physiological features in competitions. The high ranking in success scores in the teams that had low body image perception averages might be interpreted as the teams want to compensate their features which they think they are weak with other features which they feel competent. Sportsmen compensated their low body image perception scores by being successful in competitions. In addition, when the cities and conditions of the locations of the universities were considered, it was observed in the study that the geographical position, the properties of the regions, development levels, and social differences were not influential in success rating.

As a result, it may be claimed that sportsmen cannot use efficiently the reliability and motivation brought by high body image perceptions in competitions for their benefits and in a way to contribute to their scores.

\section{References}

Bektaş, Y. (2004). Ergenlerde beden imgesi üzerine bir çalışma. TürkPsikolojik Danışma ve Rehberlik Dergisi, 22, 67-75.

Berscheid, E., Hatfield [Walster], E., \& Bohrnstedt, G. (1972). Body image - A Psychology Today Questionnaire. Psychology Today, 6, 57-67.

Brownell, K. (1991). Dieting and the search for the perfect body: where physiology and culture collide. Behavior Therapy, 22(1), 1-12. https://doi.org/10.1016/S0005-7894(05)80239-4

Butler, R. (1998). Age Trends in the Use of Social and Temporal Comparison For Self Evaluation: Examination of A Novel Developmental Hypothesis. Child Development, 69(4), 1054-1073. https://doi.org/10.1111/j.1467-8624.1998.tb06160.x

Dale, L., Cusumano, J., \& Kevin, T. (1997). Body image and body shape ideals in magazines, Exposure, awareness and internalization. Sex Roles, 37(9/10), 701-721.

Featherstone, M. (2010). Body, Image and Affectin Consumer Culture. Body \& Society, 16(1), 193-221. https://doi.org/10.1177/1357034X09354357 
Gökdoğan, F. (1988). Orta Öğretima Devam Eden Ergenlerde Beden imajından Hoşnut Olma Düzeyi. Yayınlanmamış Yüksek Lisans Tezi. Ankara Üniversitesi, Sosyal Bilimler Enstitüsü.

Kjelsas, E., \& Augestad, L. (2004). Gender, Eating Behavior, and Personality Characteristics in Physically Active Students. Scandinavian Journal of Medicine \& Science in Sports, 14(4), 258-268. https://doi.org/10.1111/j.1600-0838.2003.00343.x

Lindwall, M., \& Hassmen, P. (2004). The Role of Exercise and Gender for Physical Self-Perceptions and importance Ratings in Swedish University Students. Scandinavian Journal of Medicine \& Science in Sports, 14(6), 373-380. https://doi.org/10.1046/j.1600-0838.2003.372.x

Morris, A., Cooper, T., \& Cooper, T. (1989). The changing shape of female fashion models. Int. J. Eat. Disord, 5, 593-596. https://doi.org/10.1002/1098-108X(198909)8:5<593::AID-EAT2260080511>3.0.CO;2-H

Morrison, T., Kalin, R., \& Morrison, M. (2004). Body Image Evaluation and Body Image Invesment Among Adolescents: A Test Of Sociocultural and Social Comparison Theories. 39(155), 571-592.

Ogden, J., \& Evans, C. (1996). The problem with weighing: effects on mood, self-esteem and body image. Int J Obesity, 20(3), 272-277.

Philips, J., \& Drummond, M. (2001). An Investigation Into the Body Image Perception, Body Satisfaction and Exercise Expectations of Male Fitness Leaders: Implications for Professional Practice. Leisure Studies, 20(2), 95-105. https://doi.org/10.1080/02614360121879

Richman, E., \& Shaffer, D. (2000). If You Let Me Play Sports : How Might Female Sports Partcipation Influence the Self-Esteem of Adolescent Females. Psychology of female Quarterly, 24(2), 189-199. https://doi.org/10.1111/j.1471-6402.2000.tb00200.x

Solomon, M., Venuti, J., Hodges, J., Ianuzzelli, J., \& Chambliss, C. (2001). Educational Responses to Media Challenges to Self Esteem : Body Image Perceptions Among Undergraduate Students. Eric Reports Research (143), 1-22.

Turner, S., McFarlane, A., \& Van Der Kolk, B. (1996). The Therapeutic Environment and New ETraumatic Stressxplorations in the Treatment of Posttraumatic Stress Disorder. In B. Ed. Van Der Kolk, M. Alexander C., \& L. Weisaeth, Traumatic Stress: The Effects of Overwhelming Experience on Mind, Body and Society (pp. 537-558). NewYork: Guilford Press.

\section{Copyrights}

Copyright for this article is retained by the author(s), with first publication rights granted to the journal.

This is an open-access article distributed under the terms and conditions of the Creative Commons Attribution license which permits unrestricted use, distribution, and reproduction in any medium, provided the original work is properly cited. 